\title{
The effect of automated information systems on the Kenyan county government's operations: A case study of Kiambu county government
}

\author{
Muraya Brenda Wairimu and Richard B. Nyaoga*
}

Department of Accounting, Finance \& Management Science, Egerton University, Nakuru, Kenya

\begin{tabular}{l}
\hline C H R O N I C L E \\
\hline Article history: \\
Received September 1, 2017 \\
Received in revised format \\
September 112017 \\
Accepted November 212017 \\
Available online \\
November 212017 \\
\hline Keywords: \\
Operations \\
Automated information systems \\
Improve \\
County government
\end{tabular}

\section{Introduction}

Information and Communication Technology (ICT) has become the primary tools for rendering or providing a competitive advantage for companies and organizations in all sectors of the economy (Odubanjo, 2009). The recognition of the need for the implementation and use of Information Systems has globally risen (Lipaj \& Davidavičienè, 2013). This is due to the great solutions they are capable of presenting. They are used in dealing with not only internal but also external tasks related to day to day operations and decision making (Pabedinskaite, 2010). Within different parts of an organization, there is Information System (IS) support work coordination (Basahel \& Irani, 2010). The current Kenyan agenda at the county levels is to automate all public revenue collection processes (Atsiaya et al., 2014). The 2010 Kenyan constitution required that most of the public services be devolved to the county government (Ndunda et al., 2015). That has the effect of transferring some level of independence and accountability to the county level in Kenya.

* Corresponding author.

E-mail address: nnyaoga@yahoo.com (R. B. Nyaoga)

2018 Growing Science Ltd.

doi: $10.5267 /$ j.ac.2017.11.002 
With the aim of promoting accountability and transparency, the Kenya County Government implemented the E-Practices such as Automated Information Systems. However, this technology has so far been fully implemented in nine out of the forty-seven counties in Kenya: Nairobi, Kiambu, Mombasa, Kisumu, Nakuru, Meru, Bomet, Baringo, and Embu. The first county to adopt the AIS in Kenya was Nairobi (Okiro, 2015). The implementation of AIS is mostly due to their capability to improve productivity, quality, innovation and flexibility of services and ultimately leading to higher work-related outcomes (Trivellas \& Santouridis, 2013).

Kiambu County is one of the forty-seven counties in Kenya. There are twelve sub-counties in Kiambu County: Kiambu, Ruiru, Lari, Thika, Gatundu North, Gatundu South, Juja, Limuru, Kiambaa, Kabete, Githunguri, and Kikuyu which are further subdivided into 60 wards. One of the strategic ICT objectives listed by Kiambu county is the progressive development and upgrading of the ICT connectivity and infrastructure within the county (Ndirangu, 2015).

Automation in Kiambu County commenced in 2014, on April 07, 2014 Strathmore University in collaboration with Namu and iPay implemented a pilot in Gatundu North and South Sub-Counties in Kiambu County. It enabled residence to make online applications for single Business Permits and receiving electronic Single Business Permits while allowing county official to track application status through the AIS. It also allowed online property registration, property transactions, land rate and arrears payments, on the ground revenue collection through the Point of Sale (POS) terminals monitored using the AIS as well (Nguli et al., 2016).

In addition, users of the county's payment system can make payment using mobile money, debit cards, over the counter payments, which are all reflected by the AIS. The Kenya Commercial Bank (KCB) group launched a Kiambu county Digitika Program, which was aimed at boosting revenue collection and management. This solution was an initiative that was provided in order to enhance service delivery to citizens in the ongoing devolution process by the use of Huduma cards (Ndirangu, 2015). Through the AIS, the county's citizens' payment transactions and payments made to supplies by the counties are monitored and supervised online, as well as the movements of the field agents.

In Kiambu County, the AIS are categorized into three. The first provides information regarding payments made by citizens on their own or at the county offices using mobile money, E-Wallet or cash which is the County Pro System by Strathmore, Namu, and iPay. The second gives information regarding all transactions made using the Point of Sale (POS) terminals, which is a Riverbank solution known as Zizi, where citizens can make payment using mobile money, debit/credit/visa cards, E-Wallet or cash. The final is the IFMIS which was first implemented in the National Government, and later, the local government. It is used to create transparency in the procurement processes within the government through the oracle portal. Hence, this means that the Kiambu county government evolved from using the manual systems to the automated systems (Nguli et al., 2016).

Manual systems required so many intermediaries and required great resources for operations to be performed (Ndunda et al., 2015). The financial officer who would be in-charge of all financial transactions would have to depend and trust that what was presented to them at the end of the day was the actual amount received and paid out by the county. The revenue officers had to physically go to the field to ensure that the county officials spent their days at their workstations. The receipts, invoices, and purchase orders had to be counter checked, manually processed and the amounts manually summed up making the possibility of errors high. The procurement processes were subject to manipulation and collusion between the suppliers and purchasing county officials (Kahari et al., 2015). This made the manual procedures long, tedious and open to unethical practices. The manual systems were therefore slow in providing the services to the clients or citizens and information gathered was bulky. They were time-consuming, costly, space demanding and required a large personnel size. Annual internal and external auditing was also lengthy, tedious and expensive making audits unreliable to some extent (Okiro, 2015). Consequently, fewer funds were reported at the end of the each day, slow customer and supplier service, absenteeism and presentism, dishonest practices and hence customer and supplier complaints were more each day. Hence, the county government was unable to perform efficiently its 
function of improving the welfare of the general public through devolution. As a result, it caused a negative effect on the citizens and country in general. This is since the economic growth and development of the nation was slow and at times stagnant (Maina, 2015). Therefore, the implementation of the AIS affected the operations of the County Government. Therefore, this study established the effect the implementation of the Automated Information Systems has had on the Kenya County Governments' operations.

\section{Theoretical Review}

\subsection{Technology Determinism Theory}

The theory was originated by an American Sociologist and Economist, Thorstein Veblen (Ellul, 1967). The theory implies that within a society, technology is an independent force that drives change. Hence, it seeks to explain the interaction between technology and society. It is a reductionist theory which implies that the development of structures and cultural values within a society are influenced by technology (Veblen, 1899). Technology inventions are made to enhance the performance of a certain aspect, task or thing.

The theory is both in hard form; where the changes brought by technology advancement are inevitable and soft form; where technology is an influencing factor of change. However, the theory is under the assumption that all the interactions, between technology and society, must take place in an economy which is governed by a market and the driving force is profit (Kline, 2015). This is referred to as the economic milieu. Self-determination brings about the intrinsic of technology which results in an impact on society, which shapes it. This view takes society to be a self-organizing system (Kline, 2015).

\subsubsection{The Sandcone Model}

The originality of the Sandcone Model was developed in the 1990s by Ferdows and De Meyer (Saufi et al., 2012). It explains what should happen when an operation is designed, and its activities planned and controlled. According to the Sandcone theory, there is the best sequence for improvement, based on set priorities (Slack et al., 2010). These priorities include: quality, dependability, speed of internal throughput, flexibility to response and cost. It requires that once we proceed to the next priority, focus on the previous should not be dropped. Hence it is not only a sequential process but also a cumulative one.

\subsubsection{Technology Acceptance Model (TAM)}

TAM was first introduced by Davis in 1986 and is a known and tested theory in the field of Information Systems (Alharbi \& Drew, 2014). TAM theory addresses the users' issues and their attitude towards using technology and the actual usage. Essentially, there are two cognitive beliefs that surround this theory. The first is the perceived usefulness of the technology and the second is the perceived use (Park, 2009). Davis later refined it and hence currently, according to TAM, the use of technology system by a person is influenced directly or indirectly by the intentions, attitudes, perceived usefulness of the system, and perceived ease of the system. It also proposed that external factors affect the intentions and actual use through mediated effects on perceived usefulness and perceived ease of use (Park, 2009).

\subsection{Automated Information Systems}

\subsubsection{Zizi System}

Each of the systems has solutions that they present to the Kiambu County Government. Through the Zizi System, the field agents are able to use advanced POS terminals which have distinct components that have their distinctive capabilities and perform specific functions. First is the barcode reader which authenticates the receipts that are made and certificates that are issued once payment is made. This allows information regarding each transaction made on the field to be easily accessed online. The GPS is able to track the movement of the county officials; the GPRS allows the recalling of an official when the need arises. Another component is the camera which is used to take photographs as evidence in court when conflict arises during the field agent's interaction with the citizens. Finally, the Near Field 
Communication (NFC) reader provides a platform for the payment of parking fees, utility bills, licenses, land rates among others. This makes the supervision of what the field agents are doing easier. Hence, the field agents become more transparent and accountable for their actions (Maina, 2015).

\subsubsection{County Pro System}

The County Pro Systems, on the other hand, are used by the county officials at the offices. It allows them to be able to track online applications for single Business Permits, track application status, track online property registration, property transactions, land rates and arrears payments. This simplifies their record keeping and retrieval procedures and makes them provide certificates and permits more speedily fashion. Therefore, all records become accessible to the citizens through the county portal. The County Pro system therefore also increases the transparency of the county and helps reduce the collusion between citizens and officials as transactions are immediately accessible to all authorized officials through the County Pro System (Ndirangu, 2015).

\subsubsection{Integrated Financial Management Information System}

The IFMIS has been implemented in the National treasury, Ministry offices and County Government offices. It helps to attain a unified financial management system (Ochieng, 2014). This has contributed to the heightened transparency and accountability within the functions of the government. The initiators for the IFMIS project plan includes the Office of the Auditor General and the Ministry of Finance and National Planning. The implementation of IFMIS in the County Government was therefore supported by the National Government in Kenya (Kahari et al., 2015). The main components of IFMIS include: reviewing business processes to improve financial management; linking planning to budget allocation through the policy objectives; automate the supply management function; auto-reconcile revenue and payments; record and report to the Central Bank of Kenya on financial position (Kamenyi, 2016).

\subsection{County Operations}

The county government operates in an open system. Their inputs are obtained through the services delivered by the County government and the result expected in this process would either be satisfied or dissatisfied citizens. The Kenya County Government's operations mainly lead to the undertaking of different projects mainly aimed at improving social welfare and the provision of services to the citizens. The county government's operations can be summarized using the figure below:

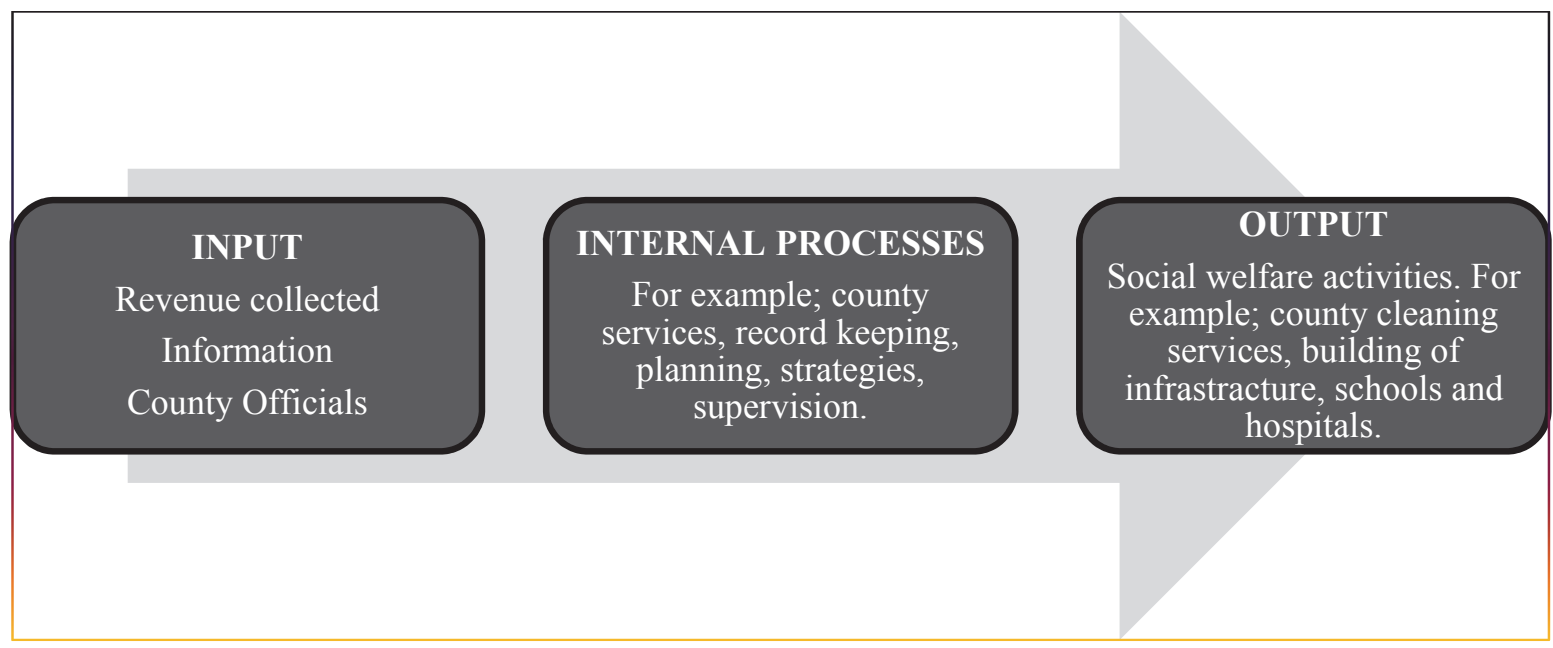

Fig. 2. County government operations

The County Government gets its revenue from taxation, permit fees, license fees and other sources (Ndunda et al., 2015). The amount is then used to source for suppliers to facilitate the performance of devolution efforts and also procure county daily utilities and supplies. Hence, supervision of transactions linked to the funds received and paid out is of great importance to ensure optimal output. 
Transparency and accountability was made possible as all payment transactions were reflected by the county government's AIS making the county operations simpler. This includes supervision since all transactions could be monitored and all field agent's movements could be monitored using the Zizi System. Another area affected is record keeping. This is since all records regarding payment were made available online once the transaction is done and a receipt issued or invoice received. This made the county government's operations to be more transparent as all revenue within the county can be monitored making those involved with the collection of revenue more accountable.

\section{Conceptual Research Framework}

The aim of this study is to establish the effect of AIS on the Kenya County Governments' operations. Based on a literature review, first, three Information Systems (ZIZI, COUNTY PRO, and IFMIS) have been identified. Second, County government Operations based on record keeping, transparency and Supervision have been identified. Fig. 1 summarizes the conceptual research framework.

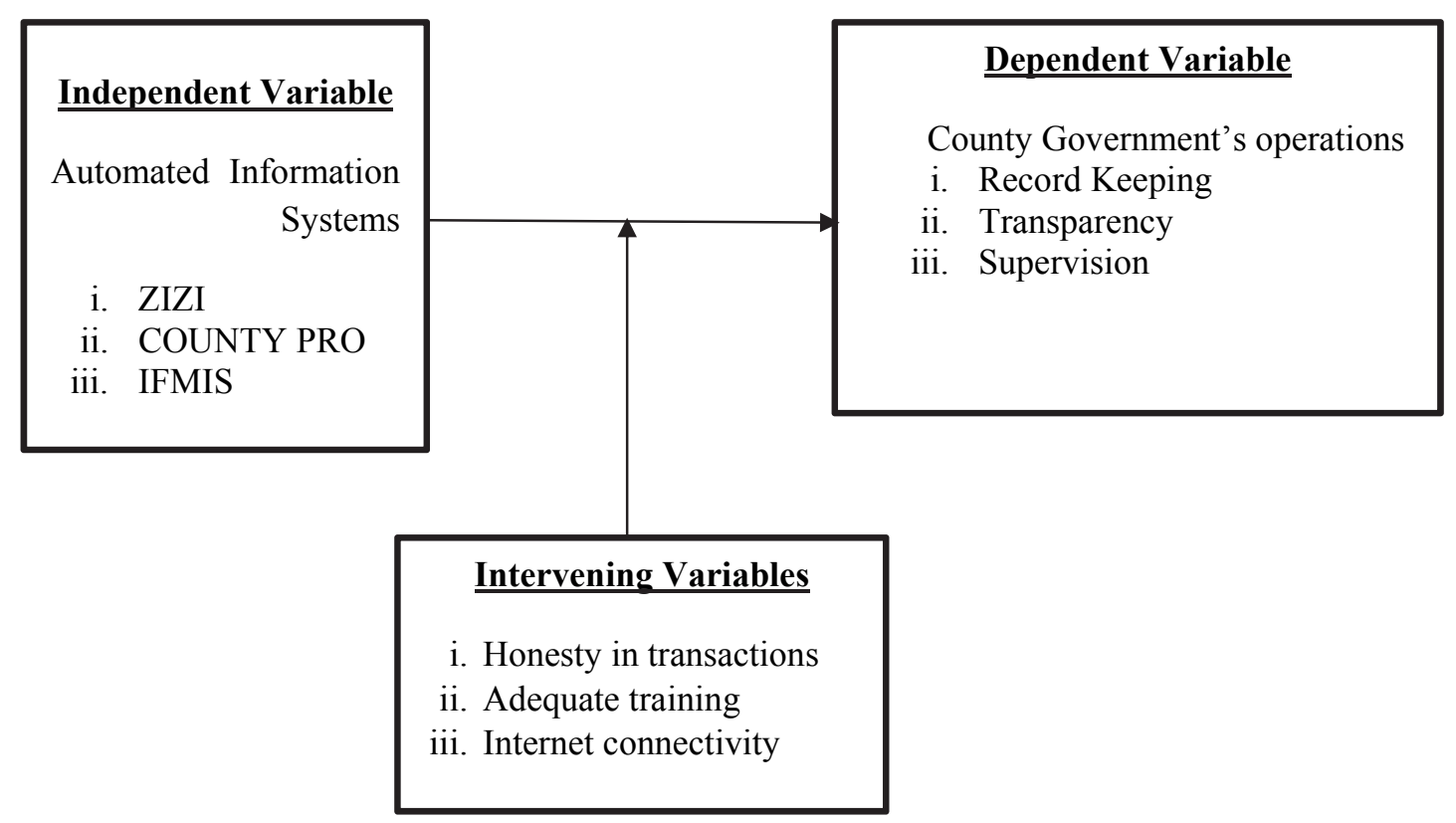

Fig. 1. A Conceptual Framework

\section{Material and methods}

\subsection{Data Collection and the Sample}

The study employed descriptive research design and used complete enumeration survey method where the target population of this study included 36 respondents from Kiambu County. This is since it was ranked the best performing county after the implementation of the systems in the year 2016 (Nguli et al., 2016). Data was collected from all twelve sub-counties in Kiambu. The study targeted the IT Officer, Financial Officer, and the Revenue Officer in each of the Sub-Counties. This is since the IT Officer was better placed to provide information related to the general systems and their implementation. The Finance Officer had the knowledge required to provide information on the impact it had had on their operations regarding transparency and accountability in financial transactions. Finally, the Revenue Officers who were in-charge of the field agents were targeted as they had information on the ease brought forth by the systems in terms of record keeping and supervision. Hence, the total population under study was 36 . Primary data was collected to test the three hypotheses. To test validity, the researcher sought the expert opinion of the supervisor, other lecturers and the finance, revenue and IT officers in the sub-counties. Reliability was tested using the measure of internal consistency which is represented by Cronbach's Alpha (Carmines \& Zeller, 1979). The acceptable value of alpha from the various reports ranges from 0.70 to 0.95 (Tavakol \& Dennick, 2011). In this 
study, a value of 0.7 and above was accepted. The findings from the reliability analysis were as presented in Table 1

Table 1

Reliability Analysis

\begin{tabular}{lll}
\hline Variable & Cronbach's Alpha & Number of Items \\
\hline County Pro & 0.737 & 5 \\
Zizi & 0.805 & 7 \\
IFMIS & 0.721 & 5 \\
County Operations & 0.914 & 9 \\
\hline
\end{tabular}

Table 1 shows that the researcher's findings were reliable as all values are greater than 0.7 . This is since County Pro $\alpha=0.737$, Zizi $\alpha=0.805$, IFMIS $\alpha=0.721$ and County Operations $\alpha=0.914$.

\subsection{Data Analysis Techniques}

The data from the questionnaires was screened and entered in readiness for analysis using the SPSS software. The data was then carefully analyzed and tabulated appropriately. Multiple regression was used to test whether the county operations can be predicted based on the use of the IFMIS, County Pro system, and Zizi System. The equation used was;

$$
\gamma_{c}=\beta_{0}+\beta_{1} x_{1}+\beta_{2} x_{2}+\beta_{3} x_{3}
$$

where, $\mathrm{Y}_{\mathrm{c}}=$ Estimated value of the county operations,

$\beta_{0}=$ Intercept on the Y axis,

$x_{1}=$ County Pro Systems,

$x_{2}=$ Zizi Systems,

$x_{3}=$ IFMIS,

$\beta_{1}=$ Corresponding change in the county operations as a result of the $\mathrm{x}_{1}$,

$\beta_{2}=$ Corresponding change in the county operations as a result of the $\mathrm{x}_{2}$,

$\beta_{3}=$ Corresponding change in the county operations as a result of the $x_{3}$.

\section{Discussion}

This section discusses the results obtained in this study, a summary of these results, the researchers' conclusions and recommendations.

\subsection{Findings}

Table 2 to Table 7 show the results of the correlation analysis, multiple regression analysis, ANOVA and Hypothesis test between the two variables in this study.

\subsubsection{Correlation Analysis and Hypothesis test}

The general objective of the study was to determine the effect of the implementation of the AIS on the Kenya County Government's operations. Pearson Correlation measures the strength of linear association that exists between two variables (Landau \& Everitt, 2004).

\section{Table 2}

Coefficients $^{\mathrm{a}}$ and Hypothesis Test

\begin{tabular}{|c|c|c|c|c|c|c|c|}
\hline \multirow[t]{2}{*}{ Model } & \multicolumn{2}{|c|}{$\begin{array}{l}\text { Unstandardized } \\
\text { Coefficients }\end{array}$} & \multirow{2}{*}{$\begin{array}{l}\text { Standardized } \\
\text { Coefficients } \\
\text { Beta }\end{array}$} & \multirow[t]{2}{*}{$\mathbf{t}$} & \multirow[t]{2}{*}{ Sig. } & \multicolumn{2}{|c|}{ Collinearity Statistics } \\
\hline & B & Std. Error & & & & Tolerance & VIF \\
\hline (Constant) & -.625 & .619 & & -1.009 & .320 & & \\
\hline County Pro & .200 & .107 & .219 & 4.867 & .001 & .702 & 1.425 \\
\hline Zizi & .747 & .129 & .669 & 5.809 & .000 & .726 & 1.378 \\
\hline IFMIS & .255 & .084 & .305 & 3.053 & .005 & .962 & 1.040 \\
\hline
\end{tabular}

a. Dependent Variable: County Operations 
The literature review and theoretical reasoning led to the belief that Zizi, County Pro, and IFMIS as types of AIS was used and had the effect of heightening operations in the County Government. A $\mathrm{z}$ test $(n>30)$ was used in the study at a 0.05 level of significance to test the three hypotheses in this study.

The first hypothesis was; $\mathrm{H}_{01}$ : County Pro System has no significant effect on the County Government's operations. From the test, the results presented in Table 2 were; $t=4.867$ and $p=0.001(<0.05)$. The findings indicate that County Pro System had a significant effect on the County Government's operations, the first hypothesis was therefore rejected and conclusion was made that County Pro System was a significant determinant of the Kiambu County Government's operations.

Table 3

Correlation Analysis between County Pro system and County Operations

\begin{tabular}{llllll}
\hline & & County Pro & Zizi & IFMIS & County Operations \\
\hline \multirow{3}{*}{ County Pro } & Pearson Correlation & 1 & $.522^{* *}$ & -.190 & $.510^{* *}$ \\
& Sig. (2-tailed) & & .001 & .133 & .001 \\
& $\mathrm{~N}$ & 36 & 36 & 36 & 36 \\
\hline
\end{tabular}

**. Correlation is significant at the 0.01 level (2-tailed).

Table 3 shows that; there is a significant $(0.001<0.01)$ positive and moderate $(0.5>.510<0.7)$ linear correlation between county operations and the County Pro Systems. This means that any positive influence on the implementation of the County Pro System, moderately improves the county's operations.

The second hypothesis was; $\mathrm{H}_{02}$ : Zizi System has no significant effect on the County Government's operations. The results of the test of this hypothesis are shown in Table 2 , where $\mathrm{t}=5.809$ and $\mathrm{p}=$ $0.000(<0.05)$ which indicates that the Zizi System has a significant effect on the County Government's operations. Therefore, the second hypothesis was also rejected. Consequently, the conclusion made was that the Zizi System is a significant determinant of Kiambu County Government's operations.

Table 4

Correlation Analysis between Zizi System and County Operations

\begin{tabular}{llcccc}
\hline & & County Pro & Zizi & IFMIS & County Operations \\
\hline \multirow{2}{*}{ Zizi } & Pearson Correlation & $.522^{* *}$ & 1 & -.058 & $.765^{* *}$ \\
& Sig. (2-tailed) & .001 & & .369 & .000 \\
& $\mathrm{~N}$ & 36 & 36 & 36 & 36 \\
\hline **. Correlation is significant at the 0.01 level (2-tailed). & & &
\end{tabular}

Table 4 shows that; there is a significant $(0.000<0.01)$ positive and strong $(0.765>0.7)$ linear correlation between County Operations and the use of the Zizi System. This means that any positive influence on the implementation of the Zizi System, greatly improves the county's operations.

The final hypothesis was; $\mathrm{H}_{03}$ : IFMIS has no significant effect on the County Government's operations. From the test, the results shown in Table 2 were obtained. As per Table 2, $\mathrm{t}=3.053$ and $\mathrm{p}=0.005$ $(<0.05)$ which indicates that the IFMIS has a significant effect on the County Government's operations. Therefore, the third hypothesis was also rejected. Subsequently, the conclusion made was that the IFMIS is a significant determinant of Kiambu County Government's operations.

Table 5

Correlation Analysis between IFMIS and County Operations

\begin{tabular}{llcccc}
\hline & & County Pro & Zizi & IFMIS & County Operations \\
\hline \multirow{3}{*}{ IFMIS } & Pearson Correlation & -.190 & -.058 & 1 & $.225^{* *}$ \\
& Sig. (2-tailed) & .133 & .369 & & .093 \\
\hline **. Correlation is significant at the 0.01 level (2-tailed). & 36 & 36 & 36 & 36 \\
\cline { 2 - 6 }
\end{tabular}


Table 5 shows that; there is not any statistically significant $(0.093>0.01)$ linear correlation between County operations and the IFMIS. However, there is a positive but low relationship $(0.225<0.5)$. What this means is that a positive influence on the IFMIS would cause a positive but insignificant improvement on the county's operations. This is also supported by the findings in Table 2.

\subsubsection{Multiple Regression Analysis}

This study tested the predictable relationship that exists between the independent variable (County operations) as a result of the dependent variable (AIS).

\section{Table 6}

Model Summary

\begin{tabular}{lllll}
\hline Model & R & R Square & Adjusted R Square & $\begin{array}{l}\text { Std. } \\
\text { Estimate }\end{array}$ \\
\hline 1 & $.832^{\mathrm{a}}$ & .692 & .663 & .26711 \\
\hline a. Predictors: (Constant), IFMIS, Zizi, County-Pro & &
\end{tabular}

From Table 6, there is a strong positive linear correlation of $83.2 \%$ between the AIS and the County Government's Operations. This means that the AIS significantly improved the County's operations. However, $69.2 \%$ of the total variation in the County Government's operations can be explained by the positive linear relationship between the AIS and the County's operations. The remaining $30.8 \%$ of the variation in the County's operations was caused by other factors.

Table 7

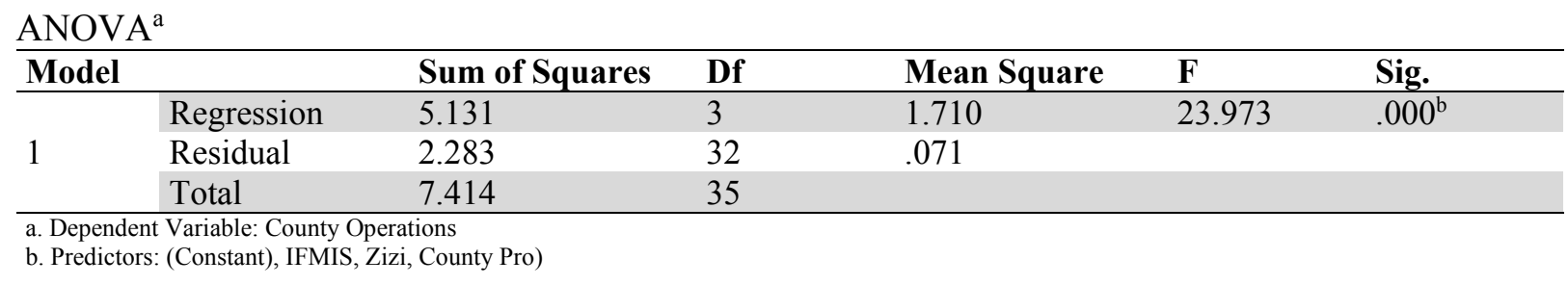

ANOVA was used to test for statistical significance of the overall effect of AIS on County Operations as illustrated on Table 7. The significant value of $.000(<0.05)$ from Table 7 shows that the effect is significant. This indicates that model (1) is a useful linear model in this study. From Table 2, the following multiple regression model was developed for the study

$$
\gamma_{c}=-0.625+0.2 x_{1}+0.747 x_{2}+0.255 x_{3}
$$

where, $\mathrm{Yc}=$ Estimated value of the county operations,

$$
\begin{aligned}
& x_{1}=\text { County Pro Systems, } \\
& x_{2}=\text { Zizi Systems, } \\
& x_{3}=\text { IFMIS. }
\end{aligned}
$$

From model (1), -0.625 is the Y-intercept of this model, indicating the level of performance achieved in Kiambu County without the adoption of AIS. The rate of change caused by the County Pro System on the County's operations is 0.2 ; by Zizi System is 0.747 , and by the IFMIS is 0.255 . Since the values are all positive, it implies that the implementation of the AIS caused a general improvement in the county operations.

As per Table 2, the Variance Inflation Factors (VIF) for the three variables is satisfactory. The VIF indicates if the variance of the weight coefficient is inflated (Tyrrell, 2009). Hence, the degree to which the weight is correlated with either of the predictors in this model is low. This is since the VIF for the County Pro System = $1.425(<5)$; of the Zizi System = $1.378(<5)$; and of the IFMIS=1.040 $(<5)$. 


\subsection{Summary of Findings}

The study established that County Pro System has a significant effect on county operations. This is because the implementation of county pro has improved the record keeping practices and heightened transparency in the County offices. This can be attributed to its record-keeping capabilities for all data regarding transactions that occur between the county officials and the county citizens. The record keeping process is automated hence; the retrieval of records regardless of the duration has been simplified. This has also increased the transparency at the County offices as the documents are easily accessible and the destruction of documents can be easily traced. This is since information is accessible on a network, meaning all officials with authorization can access all transaction data. In addition, all county documents can be supervised from the head offices in Kiambu and Thika. Every transaction made is documented which is traceable to the individual who made it. Therefore, the County Pro System has also improved supervision.

Establishing the relationship between the Zizi System and County Operations was the second objective of this study. Though, the correlation and regression of the Zizi System with County operations a significant positive relationship between the two variables was revealed. Therefore, a significant effect on county operations exists due to the implementation of the Zizi Systems. With the Riverbank Solution, the revenue collected in the field, such as the market, bus-park, parking of personal vehicles and the business premises, is recorded using the POS terminals which are connected to the county offices through the Zizi System. Hence, this information is accessed by the supervisors at the county offices through the Zizi System. This makes sure that all transactions done in the field can be accessed in the county offices making their record keeping practices easier and transparent. In addition, the POS terminals track the movements of the county field agents since it has a GPS system. This makes supervision easier as the county officials are able to track the movements of the field agents while using the Zizi System. This also increases transparency as the field agents know that their work hours can easily be monitored.

Lastly, this study aimed to determine the relationship between the IFMIS and the Kiambu County Government's Operations. It set out to determine how the use of the IFMIS has affected the County's supervision, record keeping practices as well transparency levels. Therefore, after correlating and regressing IFMIS with County operations, it was revealed that the system has a significant effect on county operations. However, the linear correlation between the variables was however positive, low and insignificant. This may be attributed to the fact that it is still not performing its function. This is as supplier records are still manual in most of the counties and hence, transparency of the procurement process is low. This therefore makes the supervision of the officials directly interacting with suppliers not to be easy and tedious.

\section{Conclusion}

ICT plays a key and leading role in national development efforts, underpinning the recognition by the government that efficient and adequate ICT infrastructure is a prerequisite for sustainable ICT sector growth. According to Ellul (1967) eventually, all tasks and work activities will be automated. IT evolves continuously; whereby new inventions either die off or become so ubiquitous that they have so much room for improvement. A few researchers have examined the trends caused by Information Communication Technology on the Kenyan economy and have in most cases had results of a significant positive relationship. For instance, Okiro (2015) concluded that the implementation of Electronic Payment Systems could improve revenue collection in the Nairobi County Government. These findings were also supported by Maina (2015).

From the findings in this study, it was evident that the three AISs have positive effects on the County government's operations. Therefore, the implementation of the AIS has had the effect of; improving the record keeping practices in the county offices; heightening the transparency of the records and transaction details in County offices; and improving supervision in the county offices. This ultimately has led to faster and more efficient operations in the County Government. In general, however, the AIS 
translated into better operations in the County Government as opposed to the use of manual systems. Therefore, the implementation of the AIS should continue to be closely monitored for superior performance, which will ensure the desired results are achieved.

Furthermore, only $69.2 \%$ variation in the county government's operations was found to be due to the use of Automated Information Systems. Hence, the use of the AIS in the County Government is a great predictor of superior operations.

\section{Recommendations}

The Kenya County Government should ensure that the level of implementation of the automated information systems is matched in each County to level up the performance levels. Hence, structures should be created and diligently adopted in the County Government to ensure uniformity in all Counties.

Further research and development should be done to identify different ways in which the use of technology can further heighten the Kenya County Government's performance levels.

The County Government should also aim to further increase awareness of the systems to ensure that citizens know the right and relevant information pertaining the use of the A.I.S. for service provision. This will help to increase the use of the systems by the citizens and reduce the queues at the county halls and sub-county offices.

In conclusion, as per the TAM theory, the perceived usefulness of IFMIS needs to be built upon. This will build the prospective subjective probability of county officials to view the system as one that will make their work easier increasing their job performance.

\section{Recommendations for Further Study}

The study focused on information provided by the county government officials who directly access information regarding operational changes. Hence, there was the isolation of potential respondents who directly interact with the systems such as field agents who could also give relevant information. Hence, further research should be done while targeting this respondent as well. The study model only explained $69.2 \%$ of the county government's improved operations due to the adoption of the automated information systems. Hence, it is recommended to conduct a similar study and include other variables that may be left out in this study.

\section{Acknowledgement}

The authors would like to thank the anonymous referees for constructive comments on earlier version of this paper. 


\section{References}

Alharbi, S., \& Drew, S. (2014). Using the Technology Acceptance Model in Understanding Academics' Behavioural Intention to Use Learning Management Systems. International Journal of Advanced Computer Science and Applications, 5(1), 143-155.

Atsiaya, B., Wanyama, K., \& Douglas, M. (2014). Effects of Total Quality Management Implementation on Electronic-Government in County Government of Kakamega. International Journal of Business and Management, 2(5), 228-233.

Basahel, A., \& Irani, Z. (2010). Examining the Strategic Benefits of Information Systems: A Global Casrs Study. In EMCIS2010 (pp. 1-17).

Carmines, E. G., \& Zeller, R. A. (1979). Reliability and Validity Assessment. London: Sage Publications.

Ellul, J. (1967). The Technological Soceity. New York: Vintage Books Publishing.

Ndirangu E. (2015). http://www.kiambu.go.ke/departments/education-ict

Kahari, C. K., Gathogo, G., \& Wanyoike, D. (2015). Assessment of Factors Affecting the Implementation of Intergrated Financial Manangement Information Syystem in the County Governments: A Case of Nyandarua County, Kenya. International Journal of Economics, Commerce and Management, 3(11), 1352-1373.

Kamenyi, D. M. (2016). Effectiveness of IFMIS in Public Sector. Nairobi.

Kline, R. R. (2015). Technological Determinism. International Encyclopedia of the Social \& Behavioral Sciences, 109-112.

Landau, S., \& Everitt, B. S. (2004). A Handbook of Statistical Analyses using SPSS. Washington, D.C: Chapman \& Hall.

Maina, L. N. (2015). The Strategic Effect of Automating Financial Systems in Devolved Governments' Perfomance: A Case of Nairobi County. Nairobi.

Ndunda, J., Ngahu, S., \& Wanyoike, D. (2015). Analysis of Factors Influencing Optimal Revenue Collection by County Governments in Kenya. International Journal of Economics, Commerce and Management, $\operatorname{III}(5), 1114-1129$.

Nguli, M., Gicaci, J., Kahiu, N., Kamau, S., \& Mungai, S. (2016). Making Kiambu the Growth Pole and Investment Hub of Kenya.

Ochieng, J. (2014). http://www.icta.go.ke/integrated-financial-management-information-systemsifmis/.

Okiro, A. (2015). The Effect of E-Payment System on Revenue Colletion by the Nairobi City County Government.

Pabedinskaite, A. (2010). Factors of Successful Implementation of ERP Systems, 15, 691-697.

Park, S. Y. (2009). An Analysis of the Technology Acceptance Model in Understanding University Students ' Behavioral Intention to Use E-Learning. Journal of Educational Technology and Society, $12(3), 150-162$.

Saufi, M., Rusuli, C., Tasmin, R., \& Takala, J. (2012). A Theoretical Study of the Sand Cone Model and Knowledge Management from Malaysian University Libraries Perspective. International Journal of Information Technology and Business Management, 1(1), 1-8.

Slack, N., Chambers, S., \& Johnston, R. (2010). Operations Management (Sixth Edit). Harlow, England: Prntice Hall, Pearson.

Tavakol, M., \& Dennick, R. (2011). Making Sense of Cronbach's alpha. International Journal of Medical Education, 2, 53-55.

Trivellas, P. G., \& Santouridis, I. (2013). The Impact of Management Information Systems ' Effectiveness on Task Productivity: The Case of the Greek Banking Sector. International Journal of Computer Theory and Engineering, 5(1), 170-173.

Tyrrell, S. (2009). SPSS : Stats Practically Short and Simple. Denmark: Ventus Publishing ApS.

Veblen, T. (1899). The Preconceptions of Economic Science. Quarterly Journal of Economics, 13, 31. 
(C) 2017 by the authors; licensee Growing Science, Canada. This is an open access article distributed under the terms and conditions of the Creative Commons Attribution (CC-BY) license (http://creativecommons.org/licenses/by/4.0/). 